\title{
Study on analysis of the causes for the failure of Antiepileptic treatment in children with seizure disorders in a tertiary centre.
}

\author{
Dr. M. Shyam Prasad ${ }^{1,}$ Dr. B. Koteshwar ${ }^{2}$. \\ ${ }^{1,2}$ (Assistant Professor of Pediatrics, Department of Pediatrics, Niloufer Hospital, Osmania Medical College, \\ Hyderabad. NTRUHS Vijayawada, India). \\ Corresponding Author: Dr. M. Shyam Prasad - drshyamprasad007@yahoo.com.
}

\begin{abstract}
:
Objective: To study and analyze the causes for the failure of Anti epileptic treatment in children with seizure disorder in relation to age, sex, type of seizure and possible etiology.

Design: Prospective observational cross sectional descriptive study.

Setting: Children between 1-14 years who are suffering with recurrent seizures who are taking AEDs were taken for the study for a period of 6months (from Jan 2011 to June 2011) who were admitted in emergency and pediatric wards of Institute of Child and Women Health, Niloufer Hospital, Osmania Medical College, Hyderabad.
\end{abstract}

Participants: Over a period of 6 months, 120 children between 1 - 14years were admitted in the hospital, were included and 3 were excluded because they are lost to follow up.

Methods: All children with recurrence of seizures who are admitted pediatric wards and in emergency were constitute the study sample. The factors causing the recurrence of seizures were studied in the preset proforma. A thorough clinical examination of the study sample is done and including the relevant investigations. The data was analyzed statistically by using ODDS Ratio, and Relative Risk ratios, Chi-square test. For all children with seizures EEG and CECT were done. Age below1 year, above 14 years, any episode without antiepileptic treatment and Myoclonic seizures, Cerebral plasy with more than 1 Anti epileptic drug, Neurocutaneous syndrome, Lenox Gestaut syndrome, West syndrome were excluded from the study.

Results: This study is comprised of 120 children ( 76 were male and 44 were female) out of which $80(66.67 \%)$ children suffered with GTCS, 33(27.5\%) suffered with complex partial seizures and remaining 7(5.83\%) with atypical febrile seizures. Noncompliance is more common in more than 6 years children than less than 6 years. The $p$ value is $<0.05$ suggests it is significant and the RR is 0.84 . Fever is the most common precipitating factor in $<6$ year children than >6 years and the odds ratio is 1.69.GTCS type of seizures is more common recurrence in the age of above 6 yrs than below 6 yrs age group. The RR is 1.29in above 6 years.

Conclusions: Male children were more commonly get recurrence of seizures (63\%). Phenytoin drug users were more likely to get the recurrence of seizures.

Key words: Anti Convulsant Drugs, drug incompliance, epilepsy and recurrent seizures

\section{Introduction}

Seizures and epilepsy ${ }^{1}$ have always affected human, although Hippocrates recognized that epilepsy ${ }^{1}$ a brain disorder if was not until the $19^{\text {th }}$ Century that modern concepts about epilepsy ${ }^{1}$ arouse. Epilepsy ${ }^{1}$ afflicts all ages but slightly more common in males and in lower socio economic groups. Epilepsy ${ }^{1}$ ncreases the risk of trauma and fracture, shoulder dislocation, burns and Aspiration pneumonia. The consequence of epilepsy ${ }^{1}$ extend far beyond seizures, long term medication and adverse effects of medication, social stigma and restrictions on education, transportation, vocation, Emotional, behavioral and family problems ${ }^{2}$. Epilepsy ${ }^{1}$ was believed to be a chronic progressive incurable disorder. Seizures were thought to cause damage and result on further seizures, clinical management of children with seizures reflected these beliefs. Over the last 25-30 years, epidemiological studies have demonstrated that. Contrary to these earlier beliefs the prognosis of most childhood seizures and epilepsy ${ }^{1}$ is excellent prognosis is largely determined by the underlying etiology and not the seizure themselves ${ }^{3}$ definitions of epilepsy ${ }^{1}$, seizures and other independent variables often are not elaborated. The classification of seizures (Commission, 1981) and epileptic syndrome (Commission 1989) proposed by the International league against epilepsy (ILAE) are either not used or a used in correctly. Almost 60-70\% of childhood epilepsies have a high chance of remission with conventional antiepileptic drugs even when used as monotherapy. Polytherapy helps to control seizures in another 10-15\% of children". Epileptic syndromes constitute $10 \%$ of all childhood epilepsies. Prognosis varies from requiring no treatment benign Neonatal convulsions, benign rolandic epilepsy to those with grave prognosis namely west's Lennox Gastaunt

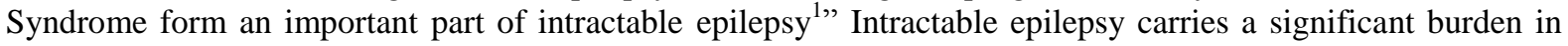


terms of drug side effects, risk of injuries and sudden death, Psychological, Cognitive and Social problems. Ketogenic diet and vagal nerve stimulates by implanted device are other options to treat intractable seizures ${ }^{4}$.

Seizure (Convulsion) ${ }^{5}$ : Defined as a Paroxysmal involuntary disturbance of brain function that may manifest as an impairment of loss of consciousness, abnormal motor activity, behavioral abnormalities sensory disturbances or autonomic dysfunction. Some seizures are characterized by abnormal movements without loss or impairment of consciousness.

Epilepsy: Defined as recurrent seizures unrelated to fever or to on Acute cerebral insult ${ }^{3}$.

Intractable Seizures: Defined as failure of two appropriate first line drugs in adequate doses used for a period of 3-6 months.

Recurrent Seizures: Two unprovoked seizures greater than 24 hours apart suggest the presence of an epileptic disorder within the brain that will lead to future recurrences ${ }^{3}$.

\section{International League Against Epilepsy (I Lae) Seizure Classificaiton Generalized Seizures}

1. Absence

a. Typical

b. Atypical

2. Generalized tonic and clonic

3. Tonic

4. Clonic

5. Myoclonic

6. Atonic

7. Infantile spasms

\section{Partial Seizures}

1. Simple partial (consciousness retained)

2. Motor

3. Sensory

4. Autonomic

5. Psychic

6. Complex partial (consciousness impaired)

7. Simple Partial followed by impaired consciousness impaired at onset.)

8. Partial seizures with secondary generalization.

UNCLASSIFIED SEIZURES

\section{Clinical Manifestations:}

Partial Seizures: Two main types, simple and complex, depending on whether consciousness. It is critical to drive, operate dangerous equipment and perform certain other activities usually has to be restricted in people with uncontrolled complex partial seizures. Most partial seizures arise in the temporal or frontal lobe ${ }^{3}$.

Simple Partial seizures: In simple partial seizures the patient is alert and is able to respond to the questions or commands and afterwards remember what happened during the seizure. This is preceded by an aura. Aura may also precede a complex partial or generalized seizure. The diversity of symptoms in simple partial seizures can make diagnosis challenging and minor or vague symptoms may go on noticed.

Motor Seizures: Can cause a change in muscle activity, Partial tonic (Neck stiffening sustained deviation of eyes to one side or clonic, jerking) movements is the most common. The abnormal movements may be restricted to one body part or spread to other muscle on the same side. (Jacksonian epilepsy) or both sides (secondary generalization of the body).Some partial motor seizures cause weakness of one or more body parts (including the vocal apparatus, affecting the ability to speak. A partial motor seizure may be followed by weakness or paralysis in the affected region. The presence and severity of weakness, however does not necessarily correlate with the intensity of tonic or clonic involvement during the seizure. Usually paralysis lasts for less than 2 hours (24hours at most) if it is prolonged todds paralysis suggests a structural cession such as tumor or stroke.

Sensory Seizures: Often cause hallucinations or illusions. Tactile sensory (somatosensory) hallucinations may remain restricted to one Area (Paresthesia in a finger) or other areas (entire upper limb). Hallucinations and illusions can involve any of the senses - touch, smell taste, vision and hearing with vestibular involvement as well. 
Autonomic Seizures: Commonly cause changes in heart or breathing rate, sweating or strange or unpleasant sensation in the abdomen, chest or head.

Psychic Seizures 5: Arise from limbic and neocortical areas, affect how the patient thinks feels and experience things. Patients report that they all in a "dreamy state" or that, they are "fully conscious". Even though their level of attention and other cognitive functions are impaired, these seizures can disrupt language function, perception and memory and can evoke spontaneous motions such as fear, anxiety, depression or happiness. Other psychic seizures evoke déjà vu, jamais vu, depersonalization, decentralization and other dissociate Phenomena such as Autoescopy, (out of body experience or seeking one's double)

Complex Partial Seizures:- In these seizures, formerly called temporal lobe or psychomotor starting is typically accompanied by impaired and recall. The patient might respond "No, no not that" regardless of the question asked. Automatic movements (Automatisms) occur in most complex partial seizures and involve both the mouth and face (Lip smacking, chewing) Upper limbs (tumbling, picking), vocal apparatus (grunts, repetition of words or phrases, or more complex acts such as walking or mixing foods. In a bowl less common automatisms include screaming, running, shouting bizarre and sometimes sexual movements and disrobing. A complex partial seizure usually lasts from 30 seconds to 3 minutes. Auras commonly precede the impairment of consciousness by seconds. After the seizure, Lethargy and confusion are common and usually last for less than 15 minutes. Partial seizures can spread (secondarily generalize) to become tonic-clonic an aura. A tonic-clonic seizure that beings as a partial seizure may be difficult to distinguish from a generalized tonic-clonic seizure, EEG and Neuro imaging tests help distinguish these seizure types ${ }^{2}$.

II Generalised Seizures: The principal types of generalized seizures are absence, Atypical absence, myoclonic, atonic, tonic and tonic-clonic.

Absence Seizures: Brief episodes (2-15 seconds) of starting with impairment of awareness and responsiveness being without warning and end suddenly leaving the person alert and attentive. Absence seizure usually begin between ages 4 and 14 years and often resolve by age 18 since Hyperventilation can provoke absence seizures, it is an effective way to reproduce seizures during diagnostic evaluation. Development and intelligence are usually normal.

\section{In Simple Absence Seizures:}

The patient only has starting spell. In the more common absence seizure, starting is accompanied by motor phenomena (eye blinking, brief automatic month, or hand movements, changes in muscle tone) especially if the Seizure Lasts More Than 10 Seconds.

Atypical Absence Seizures: These seizures also begin before the age of 6 years, but unlike absence seizures, atypical absences may start and end gradually over seconds, often last more than 10 seconds and are usually not provoked by rapid breathing. They stare but may experience only partial reduction in responsiveness. Blinking of the eyes or slight jerking movements of the lips may occur. Atonic and tonic seizures are common. Since children with atypical absence seizures usually have sub average intelligence, atypical absence seizures can distinguish from the child's usually behavior².

Atonic Seizures: Usually beginning in childhood, atonic seizures (lasting for less than 15 seconds) are associated with a sudden loss of muscle tone that causes the eyelids to drop in the head to nod. The patient may drop things or fall to the grounds.

Tonic Seizures: Characterized by sudden bilateral stiffening of the body arms, or legs. Tonic seizures usually last less than 20 seconds and are common during sleep.

Myoclonic Seizures: Myoclonus, a brisk-shock like jerk of muscle and group of muscles often occurs in healthy people as they fall asleep. Pathologic Myoclonus can result from epileptic and non-epileptic causes.

Epileptic myoclonus usually causes synchronous and bilateral jerk of the neck shoulders upper arms body and upper legs. Myoclonic seizures occur in a variety of epilepsy syndromes.

Generalised Tonic-Clonic Seizure: Theses seizures are commonly called "Grand Mal, convulsion: Tonic Clonic seizures begin with loss of consciousness, a tonic phase (Stiffening) a fall, and often a cry caused by air forced through the contracted vocal cords. The subsequent clonic phase consists of jerking of the upper and lower limbs tonic - clonic seizures usually last 1 to 2 minutes.

Other manifestations after the seizure are include drooling or foaming, excessive saliva production, biting of the tongue, cheeck or lip and bladder or bowel incontinence (postictal phase). The patient is usually Lethargic and confused for minutes to hours and often falls asleep. Agitation or depression may also occur these seizures usually first occur in childhood or in early adulthood.

\section{Material And Methods}

A prospective observational cross sectional descriptive study was designed, children between 1- 14 years with recurrent seizures on AED were taken into the study for period of six month that is from January 2012 to June 2012. Approval was taken from the ethics committee of Osmania medical college, Hyderabad. Informed consent was taken from parents/guardian. Total number of cases studied were 120.A thorough, history 
and clinical examination of the study sample is done and including the relevant investigations. The data was analyzed statistically by using ODDS Ratio, and Relative Risk ratios, Chi-square test. For all children with seizures EEG and CECT were done. Statistical analysis is performed applying MICROSOFT EXCEL 2007. EPI. INFO.3.5.3.

\section{A. Inclusion Criteria}

1. Age group between 1-14 years.

2. Child should be an Anti Epileptic treatment

3. Second episode of seizure or more than second episode of the seizure.

\section{B. Exclusion Criteria}

1. Age group below 1 year.

2. Age group above 14 years.

3. Any episode without antiepileptic treatment.

4. Myoclonic seizures, Cerebralplasy with more than one Anti epileptic drug, Neurocutaneous syndrome, Lenox Gestaut syndrome, West syndrome.

\section{Observations And Results}

Total of 120 children with recurrent seizures were studied in the age group of 1-14 years during the period. January 2012 to June 2012.

An epidemiological analysis of these patients is not made as patient come to this hospital from Hyderabad and different parts of the State (Andhra Pradesh) including Karnataka and Maharastra. Most of these patients are from lower socio-economic class, hence there cannot be any correlation between the incidence of recurrence of seizures in various religious and geographical groups of the population. Therefore the study of the children is made to note the profile of its Hospital based incidence.

Table No. 1

\begin{tabular}{|l|c|c|}
\hline Type of Seizure disorders & Number & Percentage \\
\hline GTCS & 80 & $67 \%$ \\
\hline Complex partial seizures & 33 & $28 \%$ \\
\hline Atypical febrile seizures & 07 & $07 \%$ \\
\hline TOTAL & $\mathbf{1 2 0}$ & $\mathbf{1 0 0 \%}$ \\
\hline
\end{tabular}

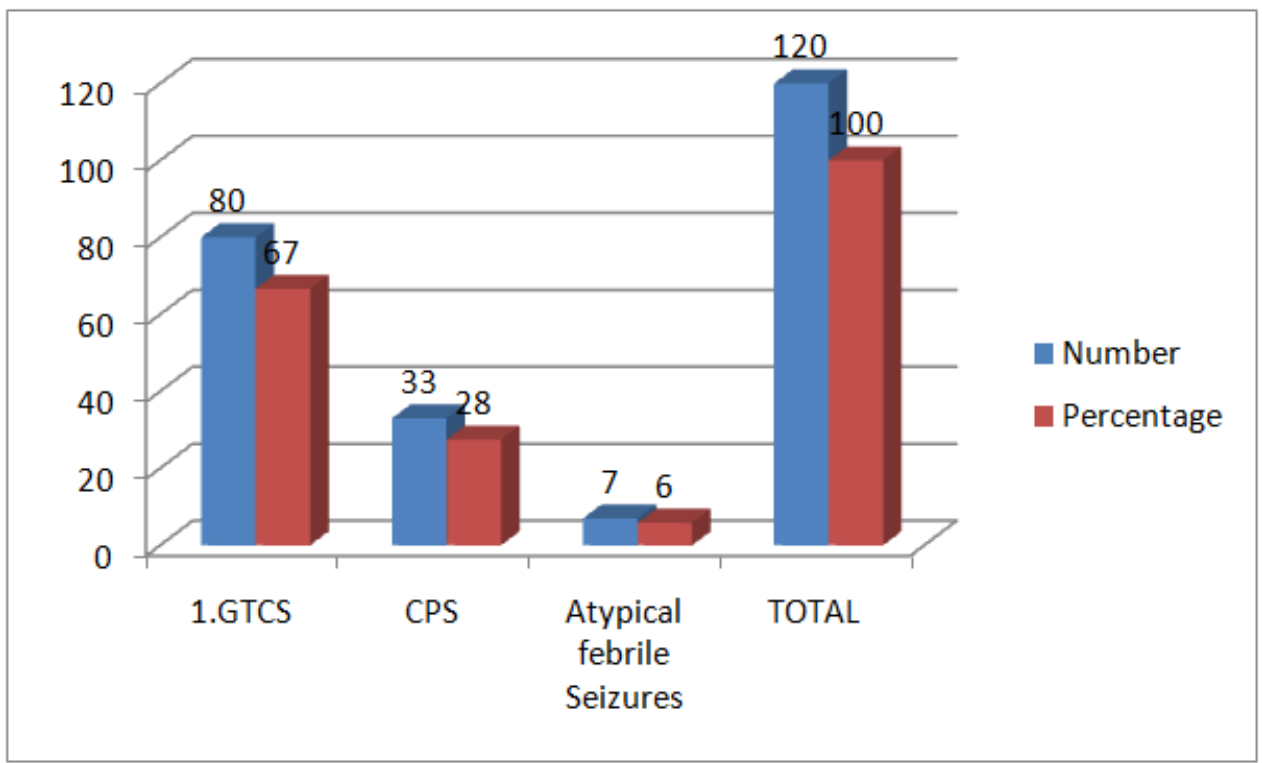

Figure 1: Diagram Showing Type Of Seizure Disorders

Table No. 2. Distributions Of The Children According To The Gender.

\begin{tabular}{|l|c|c|}
\hline Sex & No. of cases & Percentage (\%) \\
\hline Males & 76 & $63 \%$ \\
\hline Female & 44 & $37 \%$ \\
\hline TOTAL & 120 & $100 \%$ \\
\hline
\end{tabular}




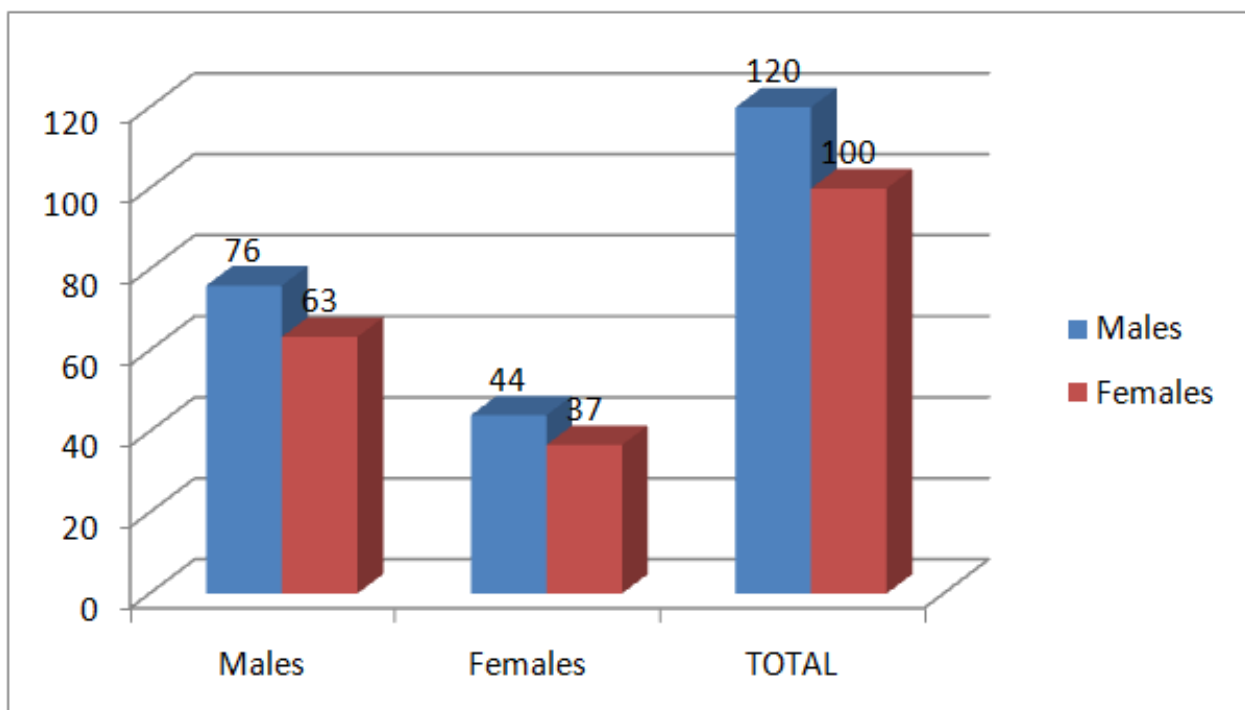

Figure 2: Diagram Showing Gender In Children

Table No. 3

\begin{tabular}{|c|c|c|}
\hline Age & No. of cases & Percentage (\%) \\
\hline Years & 34 & 28.33 \\
\hline 6-10 years & 46 & 38.33 \\
\hline > 10 years & 40 & 33.33 \\
\hline TOTAL & $\mathbf{1 2 0}$ & $\mathbf{1 0 0 \%}$ \\
\hline
\end{tabular}

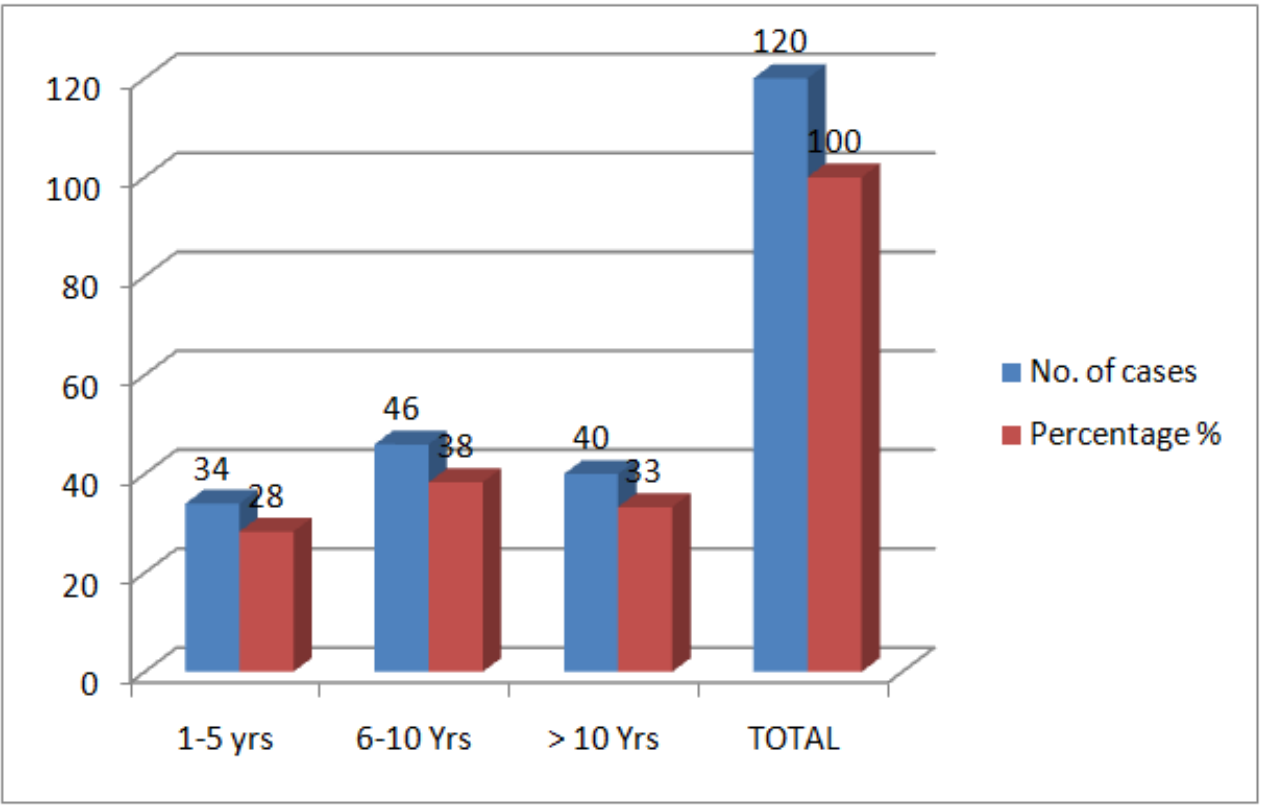

Figure 3: Diagram Showing Age With Percentage Of Cases

Table.4. Distribution of children ppt factor fever and other factors

\begin{tabular}{|l|c|c|}
\hline & Present & Percentage \\
\hline Fever & 39 & $32 \%$ \\
\hline Some other & 81 & $68 \%$ \\
\hline TOTAL & $\mathbf{1 2 0}$ & $\mathbf{1 0 0 \%}$ \\
\hline
\end{tabular}




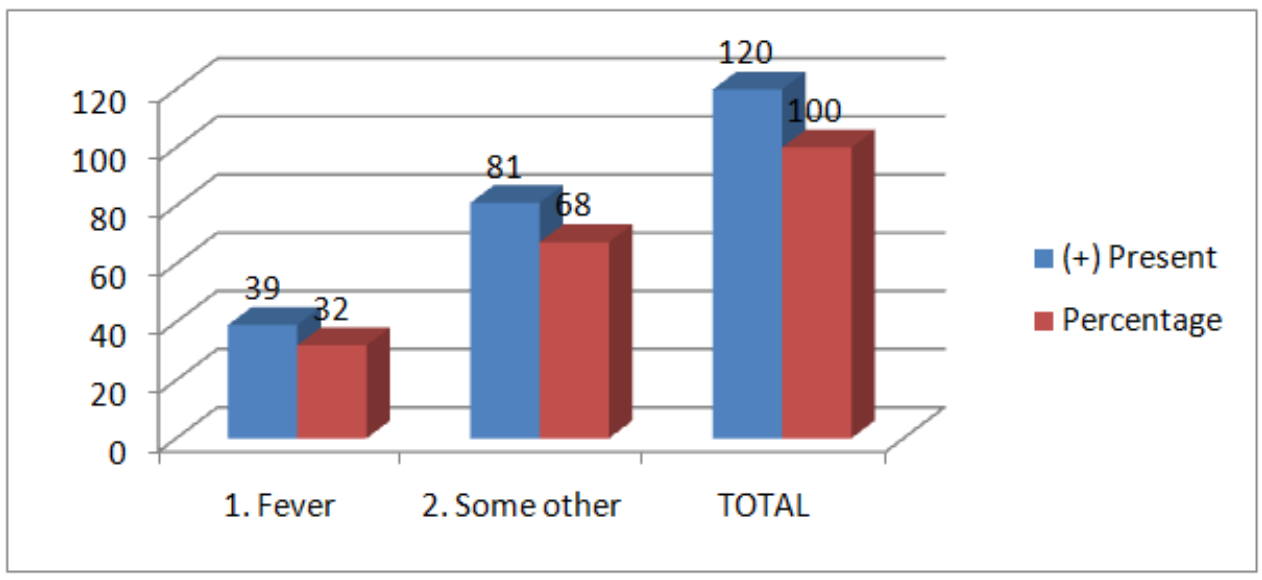

Figure 4. Diagram Showing Seizure Precipitating Factors And Other Factors

Table.5. Distribution of children, According to probable etiological Diagnosis and distribution of seizures

\begin{tabular}{|l|c|c|}
\hline Underlying cause & No. of children & Percentage \\
\hline Idiopathic & 69 & $58 \%$ \\
\hline $\begin{array}{l}\text { Inderlying Cause Disorder Mental retardation, Focal Neurological deficit, Microcephaly, } \\
\text { Hydrocephalus, ICSOL }\end{array}$ & 21 & $18 \%$ \\
\hline Family H/o. epilepsy & 15 & $13 \%$ \\
\hline Head injury & 7 & $7 \%$ \\
\hline Birth Asphyxia (HIE) & 4 & $3 \%$ \\
\hline Post meningitis sequalae & 2 & $2 \%$ \\
\hline Underlying metabolic Disorders & 2 & $2 \%$ \\
\hline Cerebal Abscess due to CSOM & 2 & $2 \%$ \\
\hline Post encephalitic sequalae & 1 & $1 \%$ \\
\hline TOTAL & 120 & $100 \%$ \\
\hline
\end{tabular}

Table 6.Distribution of children according to probable underlying causes

\begin{tabular}{|l|c|c|}
\hline Cause & No. of Children & Percentage \\
\hline Drug non compliance & 52 & $43 \%$ \\
\hline Fever ppt the seizure & 21 & $18 \%$ \\
\hline Inadequate dosage & 17 & $14 \%$ \\
\hline Idiopathic (unknown) & 8 & $6 \%$ \\
\hline Inappropriate selection of drug & 4 & $4 \%$ \\
\hline Stress (beaten by teacher) & 1 & $1 \%$ \\
\hline
\end{tabular}

Table No. 7 No. of Children with EEG Abnormality

\begin{tabular}{|l|c|c|}
\hline & No. & Percentage \% \\
\hline EEG Abnomality present & 79 & $66 \%$ \\
\hline EEG Normal & 39 & $32 \%$ \\
\hline EEG Not done & 2 & $2 \%$ \\
\hline TOTAL & $\mathbf{1 2 0}$ & $\mathbf{1 0 0 \%}$ \\
\hline
\end{tabular}

Table No. 8.No. of Children with abnormal CT findings

\begin{tabular}{|l|c|c|}
\hline & No. & Percentage \% \\
\hline CT Scan Abnormality & 26 & $21 \%$ \\
\hline CT Scan "Normal" & 92 & $77 \%$ \\
\hline CT Scan Not done & 2 & $2 \%$ \\
\hline TOTAL & $\mathbf{1 2 0}$ & $\mathbf{1 0 0 \%}$ \\
\hline
\end{tabular}

Out of 26 cases -24 cases were having granulomas like Tuberculoma ${ }^{2} /$ Neurocysticercosis and 1 case having ethimodial sinusitis 1 case having Basal Ganglia Calcification.

Table No. 9.Distribution of children with relation to type of Drug using

\begin{tabular}{|l|c|c|}
\hline & No. & Percentage \% \\
\hline Phenytoin & 44 & $37 \%$ \\
\hline Carbamazepine & 40 & $33 \%$ \\
\hline Valproic Acid & 28 & $23 \%$ \\
\hline Phenobarbitone & 4 & $4 \%$ \\
\hline Clobazam & 2 & $2 \%$ \\
\hline
\end{tabular}


Distribution of children, with low serum drug level in relation to the Non compliance and Inadequate Dosage of the Drug.

Non compliance

Inadequate dosage of the Drug

No. of children the Drug levels were done 59

Total No. of children with Seizures admitted are

$\begin{array}{ll}= & 16 \% \\ = & 12 \% \\ = & 50 \% \\ = & 288\end{array}$

Total No. of children admitted in the department of pediatrics during January 2012 to June 2012.

Out of 1872, Recurrences of seizures admitted were 225 and constituting $8 \%$ of total admissions.

Table No. 11. Showing the comparison with Non compliance below 6 yrs and $>6$ years

\begin{tabular}{|l|c|c|c|}
\hline Non compliance & Present & Absent & Total \\
\hline$<6$ yrs & 18 & 33 & 51 \\
\hline$>6$ yrs & 34 & 35 & 69 \\
\hline Total & $\mathbf{5 2}$ & $\mathbf{6 8}$ & $\mathbf{1 2 0}$ \\
\hline
\end{tabular}

Relative risk ratio: $0.84 \quad$ ODDS Ratio: $0.56 \quad$ P Value $<0.05$ is Significant

Non compliance in children above 6 yrs age group is more than age group $<6$ yrs probably due to child has to take tablets on his own so, there was chance of mission the Dose.

Table No. 12 showing the comparison between the GTCS type of seizure, <6yrs and above 6 yrs

\begin{tabular}{|l|c|c|c|}
\hline GTCS Type & Present & Absent & Total \\
\hline$<6$ yrs & 29 & 22 & 51 \\
\hline$>6$ yrs & 51 & 18 & 69 \\
\hline Total & $\mathbf{8 0}$ & $\mathbf{4 0}$ & $\mathbf{1 2 0}$ \\
\hline
\end{tabular}

Relative risk ratio: 1:29 ODDS Ratio: $0.46 \quad \mathrm{P}$ Value $<0.05$ is Significant

GTCS types of seizures were more commonly recurred in the age of above 6 yrs than below 6 yrs age group. There was 1.29 times the chance of recurrence.

Table No.13 Showing the seizure precipitating factor, fever, <6yrs and > 6yrs age group children.

\begin{tabular}{|l|c|c|c|}
\hline Fever & Present & Absent & Total \\
\hline$<6$ yrs & 20 & 31 & 51 \\
\hline$>6$ yrs & 19 & 50 & 69 \\
\hline Total & $\mathbf{3 9}$ & $\mathbf{8 1}$ & $\mathbf{1 2 0}$ \\
\hline
\end{tabular}

$\begin{array}{lll}\text { Relative risk ratio is } 0.66 & \text { ODDS Ratio: } 1.69 & \text { P Value }<0.05 \text { is Significant }\end{array}$

Below 6 yrs age group children had recurrence of seizure are due to fever more commonly than above 6 yrs age group.

\section{Discussion:}

Similar, study was done by Dr. Sudheer Kumar ${ }^{6}$, from Christian Medical College, Hospital, Vellore, Tamilnadu, Published in Journal of Indian Pediatrics, February, 2005. Total No. of children studied 30 (18 boys) 3-17 years age group children are included. The type of epilepsy included generalized tonic - clonic in and 11 absence, complex partial and myoclonic in 5 each and focal motor in 4 children. Brain imaging available in 13 patients was normal. Factors precipitating epilepsy were included in $11(37 \%)$ children. These included watching television in 4 (for periods ranging 1-4hrs) Seizures occurred while watching TV in 2 and within 10 minutes of stopping in other -2, Fever in 4 (seizures occurred at the peak of fever in all, playing video games (designing the activity) emotional stress and sleep deprivation no factors could be identified in the remaining 14 children.

In a recent study $62 \%$ of patients cited at least one precipitant that included stress (30\%) sleep deprivation (18\%) fever in illness (14\%) and fatigue (13\%). In conclusion, a variety of factors may play a role in precipitating seizures. A careful history could help us in identifying them. Adequate avoidance or treatment of these factors could help in better seizure control and possibly in reduction of dosage of AED's. Another similar study was done by Sarkar, Chitra etal ${ }^{7}$ in department of Neurology, at Indian Institute of Medical Sciences (AIIMS), New Delhi India, with over 153 patients over 10 years period published in Neuro India, February 2006 concluded that, most patients with intractable epilepsy have significant histopathological findings.

Another similar study, was done by Michael R. Sperling $\mathrm{MD}^{8}$, Published at Post graduate medicine, July - 1997 treatment dismissed seizure recurrence from $51 \%$ to $25 \%$ over 2 years in patients with a first tonic clonic seizure (Partial over generalized). Factors influencing seizure recurrence decreased likelihood of recurrence remitting epilepsy syndrome, single seizure (except myoclonic) Normal IQ, Normal Neurologic findings, Seizure free period $>2$ yrs Age at seizure onset $<16 y r s$. Increased likelihood or recurrence are 
unremitting epilepsy syndrome multiple seizure, myclonic seizure, mental retardation. Abnormal neurologic findings, seizure free period and $<2$ Age at seizure onset $>16$ yrs. In general studies have suggested that from $60 \%$ to $70 \%$ of children are able to successfully stop drug therapy with no seizure recurrence in the first few years after withdrawal. Most relapse $>60 \%$ occur in the first 6 months after initiation at drug paper, but relapse can occur year later in some individuals.

The presence of mental retardation vastly increases the chance of recurrence.

A recent large scale study from the united kingdom suggested that, patients with seizure onset before 16 years of age have recurrence less often than those with later onset. Another study "Therapy of resistant epilepsy in children with the view of the long term outcome" - Done by - Tateki Morikawa. MD et al'over 362 children, out of that 119 has generalized tonic seizure which were the most common seizure type in patients with generalized epilepsy. The long term observation of the patients with tonic seizures revealed that their seizures were completely controlled in 27 patients for more than 5 years. The effective Antiepileptic drug was valproic acid (10 patients). For obtaining improvement of tonic seizure, another strong factor is reducing the number of Antiepileptic drugs such as the average number of drug which was 4.7 to 2.4 in these 27 patients.

This study was published in Psychiatry and clinical Neurosciences volume, $58^{\text {th }}$ issue 3 June -2004. Another similar study was done by Vrajeesh Udani P.D et al ${ }^{10}$ Hinduja National Hospital, Medical Research centre, B.J. Wadia Hospital for children, Mumbai. This was published in Indian J.Pediatrics, 2000. Done over 123 children, these cases revealed intractable epilepsy more common in males with an onset of seizures below 2 yrs age with static or progressive neurological diseases, in the form of mental retardation / regression and abnormal neurological findings, myclonic, mixed seizure types or known epileptic syndrome. 5-20 yrs follow up study of 125 children with medically resistant seizures revealed a seizure remission rate of $4 \%$ per yr in normal / border line intelligent children and only a $1.5 \%$ remission rate in retarded children.

Seizure remains uncontrolled in $15-20 \%$ of all childhood epilepsies, despite conventional therapy. Risk factors for intractable seizures include. Early age of onset remote symptomatic seizures, certain seizure types and epileptic syndromes adverse effects of chronic epilepsy on Academic performances and future employment have been documented. Error in diagnosis and therapy often result in Pseudo-intractability.

Table No.14 Comparission With Present Study And To Other Similar Studies

\begin{tabular}{|l|c|c|c|}
\hline Sex & Sudhir Kumar $^{6}$ & Sarkar Chitra et al 2004 $^{\mathbf{7}}$ & Present Study 2005 $^{7}$ \\
\hline Male & $18(60 \%)$ & $112(72 \%)$ & $76(63 \%)$ \\
\hline Female & 12 & 41 & 44 \\
\hline Total & 30 & 153 & 120 \\
\hline
\end{tabular}

In the above 3 studies males are more common getting recurrence.

Table No.15

\begin{tabular}{|l|c|c|c|}
\hline & Sudhir Kumar $^{\mathbf{6}}$ & Tateki Marikowa et al 2004 $^{\mathbf{9}}$ & Present Study 2005 \\
\hline GTCS Type & $11 / 30(36 \%)$ & $119 / 362(33 \%)$ & $80 / 120(66 \%)$ \\
\hline
\end{tabular}

GTCS types of seizure are more common Resistant above 3 studies.

Table No.16

\begin{tabular}{|l|c|c|c|}
\hline \% Recurrence & Sudhir Kumar ${ }^{\mathbf{6}} \mathbf{2 0 5}$ & Vrajesh Udani et al 2000 $^{\mathbf{1 0}}$ & Present Study 2005 \\
\hline & $40 \%$ & $20-40 \%$ & $40-50 \%$ \\
\hline Fever & $4 / 30(14 \%)$ & $16 / 123(13 \%)$ & $21 / 120(18 \%)$ \\
\hline
\end{tabular}

Non compliance is the most common cause of recurrence of seizures, constituting $43 \%$ in our study.

\section{Summary And Conclusions}

1. GTCS, was the most common type of seizure it is presented in as recurrence.

2. Recurrences of seizures were seen in male children than female children.

3. In my study, age group between $6-10$ years $38 \%$ children were getting the recurrence of seizures, $28 \%$ of children between 1-5 years age group were least commonly getting recurrence.

4. Around $1 / 3$ rd of study sample associate with fever.

5. Etiologically the probable cause for recurrence is idiopathic, next to that underlying CNS disorders which constituted about $18 \%$ and other least common causes were underlying Metabolic Disorders and cerebral Abscess.

6. Most common cause for recurrence is Drug non compliance, next to that is fever precipitated the seizures and inadequate dosage of the drug due to lack of follow up.

7. Family history of epilepsy is also one of the contributing factor for recurrence of seizures.

8. Phenytoin drug users are more likely to getting recurrence than other AED.

9. Underlying CNS disorders like CP and MR were also significant contributing factors for the recurrence of seizures. 
Acknowledgements: The authors want to thank the parents and the guardians who consented for the participation of their children in the study.

Conflict of interest: none.

Source of funding: none

\section{Bibilography}

[1]. Epilepsy, Text book of Pediatric Neurology, Swaiman $5^{\text {th }}$ Ed, 2012;703-879.

[2]. Bhargava. S Tandon PN, Intra cranial tubercloma ACT Study, Branch.J Radial 1980;53:935-945.

[3]. Seizures in childhood: Nelson Text Book of Pediatrics, 19 ${ }^{\text {th }}$ Ed, 2012:vol II: 2013-2038

[4]. Resistant seizures - Veena Kalra: Indian Pediatrics, Jan1996:33:5-9.

[5]. Seizure Disorders: Clinical Symposia CIBA Vol.46 No.1:1994.

[6]. Factors precipitating breakthrough seizures in well controlled epilepsy - Sudhir Kumar, Journal of Indian Pediatrics February, $2005,42: 182-183$

[7]. Neuropathological spectrum of lesions associated with intractable epilepsies: A 10-year experience with a series of 153 resections Neurology India, Vol. 54, No. 2, April-June, 2006, pp. 144-150.

[8]. Epilepsy management issues in Medical and surgical treatment by Michael, R. Sperling MD - Vol. 102/No..1 (July 1997).

[9]. A Nonsense Mutation of the Sodium Channel Gene SCN2A in a Patient with Intractable Epilepsy and Mental Decline - Tateki Marikowa (2004) et al (2004)The Journal of Neuroscience, March 17, 2004 • 24(11):2690 -2698.

[10]. Evaluation and Management of Intractable Epilepsy - Vrajesh Udani Supplement- Indian J Pediatr 2000; 67;SS1: S61-S70 